\title{
Rede Escola de Governo do Rio Grande do Sul: forma- ção continuada e superação do modelo gerencialista
}

\author{
Roberta da Silva Krumel \\ Leonardo Beroldt
}

\author{
Universidade Estadual do Rio Grande do Sul, Especialização \\ em Gestão Pública, Porto Alegre, RS, Brasil. \\ E-mails: roberta-krumel@fdrh.rs.gov.br \\ leonardo-beroldt@uergs.edu.br
}

Recebido em: 11 jun. 2017. Revisado em: 3 nov. 2017. Aceito: 22 nov. 2017.

DOI: http://dx.doi.org/10.21674/2448-0479.42.161-175

\section{Resumo}

Algumas doutrinas econômicas e políticas já dominaram o cenário público no Brasil e no mundo. As reformas do Estado vêm trazendo diferentes formas de se tentar superar as crises econômicas, políticas e sociais. Nesse sentido, a Administração Pública adota diferentes modelos de gestão e diferentes maneiras de formar e capacitar seus servidores públicos para atuarem na gestão pública. As escolas de governo buscam disseminar este conhecimento em gestão pública, bem como desenvolver competências profissionais dos que compõem o Estado. Este trabalho analisa a forma adotada pela Rede Escola de Governo (REG) do Rio Grande do Sul na busca pela superação do gerencialismo. O método utilizado foi a pesquisa bibliográfica. Com esta pesquisa, percebe-se que a REG supera parcialmente o gerencialismo.

Palavras-chave: Servidores públicos. Neoliberalismo. Gerencialismo.

\section{Abstract \\ SCHOOL OF GOVERNMENT NETWORK OF RIO GRANDE DO SUL: CONTINUED TRAINING AND OVERCOME OF THE MANAGEMENT MODEL}

Some economic and political doctrines have already dominated the public scenario in Brazil and in the world. State reforms have brought different forms of trying to overcome economic, political and social crises. In this sense, the Public Administration adopts different management models and different ways of training and qualifying its public servants to act in public management. Schools of Government seek to disseminate this knowledge in public management, as well as to develop professional skills of those who compound the State. This paper analyzes the form adopted by the School of Government Network (REG) of Rio Grande do Sul in the quest to overcome managerialism. The method used was the bibliographical research. With this research, it is observed that the REG partially overcomes managerialism.

Keywords: Public servants. Neoliberalism. Managerialism. 


\section{Introdução}

Na década de noventa, a New Public Management, denominada no Brasil como Nova Gestão Pública ou Gerencialismo foi introduzida na Administração Pública brasileira no governo de Fernando Henrique Cardoso. Esse modelo "passou a ocupar um espaço quase que hegemônico no mundo, representando algo muito parecido ao que se poderia denominar de pensamento único na área da Gestão Pública" (DASSO JÚNIOR, 2002, p. 1). O gerencialismo busca a eficiência da máquina pública e foi visto como a "solução" para a crise do Estado, através das privatizações, das terceirizações, do livre mercado e da transferência de serviços públicos para o setor privado. O modelo gerencial significa trazer ferramentas da iniciativa privada para a pública (informação verbal fornecida por Gabriel E. Vitullo em aula inaugural do curso de Especialização em Gestão Pública e Democracia da UERGS, Porto Alegre, em agosto de 2013). Conforme Bresser Pereira (1996), havia a necessidade de uma modernização da administração pública, e essa modernização só seria possível através da perspectiva gerencial, pois esta tornaria a gestão pública eficiente, controlada por resultados, voltada para o atendimento do cidadão-cliente.

O gerencialismo faz parte do ideário neoliberal, o qual tem uma história longa de consolidação e disseminação no mundo. O neoliberalismo tem como premissa a construção de um mercado autorregulado e sem obstáculos e um Estado reduzido a sua mínima expressão (VITULLO, 2011). Para os neoliberais, o capitalismo e as liberdades individuais necessitam ser protegidas, e o Estado deve interferir minimamente na economia e no social, pois, assim, os indivíduos teriam que se esforçar mais, trazendo progresso moral e material à sociedade.

Nesse contexto, surge a questão sobre a formação do servidor público. Conforme Dasso Júnior (2002), é muito importante trabalhar o perfil do funcionário público para o serviço público, e não apenas utilizar um programa de formação da área privada, adaptando-o para a área pública. Porém, se o gerencialismo busca soluções na iniciativa privada, há o risco de que se formem servidores públicos não aptos a lidar com as questões demandadas pela sociedade, pelo cidadão que é usuário dos serviços públicos. Para Frigotto (2013), o tema da formação e capacitação do servidor público passa pela construção de sujeitos autônomos, solidários e protagonistas para atuar na gestão pública.

O presente estudo buscou analisar de que forma a Rede Escola de Governo (REG) do Rio Grande do Sul representa uma tentativa de superação do modelo gerencialista da Administração Pública. Para isso, parte da discussão sobre doutrinas econômicas e políticas ao longo da história, modelos de gestão pública, formação do servidor público, para, na sequência, analisar o caso específico da REG.

Este artigo está estruturado de maneira a possibilitar uma reflexão a respeito da gestão pública brasileira. Inicia mostrando sobre a teoria neoliberal. Na sequência, aborda a crise do Estado que levou à adoção do modelo gerencialista e após, aborda sobre a necessidade de formar o servidor público para atuar na gestão pública e sobre a pedagogia da gestão pública democrática. Em seguida é descrito o método adotado, e, por fim, é descrita e analisada a concepção doutrinária que a REG se utiliza para atingir seu objetivo de superar o modelo gerencialista praticado na administração pública. 


\section{A teoria neoliberal}

Para abordar o tema do gerencialismo, é preciso estudar a sua história, origem e concepção. O gerencialismo faz parte do ideário neoliberal, portanto nesse item serão analisados a origem do neoliberalimo, seus objetivos e premissas.

Neoliberalismo: breve histórico: Neoliberalismo é o ressurgimento de ideias associadas ao liberalismo. Pode-se considerá-lo uma doutrina econômica e política. Conforme Vitullo (2011), dois episódios marcaram o nascimento da ideologia neoliberal: o Colóquio Walter Lippmann, que ocorreu em 1938 em Paris, e uma reunião nos Alpes Suiços, que ocorreu em 1944. No Colóquio foi realizada a discussão da obra "A boa sociedade", manifesto anti-intervencionista de Walter Lippmann, sendo que o próprio fez parte do evento, além de Friedrich von Hayek, que publicou a obra "O caminho da servidão", considerada a "bíblia" do pensamento neoliberal, entre outras personalidades. No encontro na Suíça, mais participantes agregaram-se ao grupo e mais tarde, no ano de 1947, 36 personalidades das áreas acadêmica, política, jornalística e cultural se reuniram em Mont Pèlerin (Suíça) para discutir a construção de uma plataforma política e ideológica com o objetivo de enfrentar o planejamento e o intervencionismo econômicos e combater o Estado de Bem-Estar social. Para esses intelectuais, o capitalismo e as liberdades individuais estavam ameaçados.

Quanto à proposta dos neoliberais, esta pode ser resumida nas ideias de um mercado autorregulado e sem obstáculos, uma moeda forte, finanças públicas saneadas e um Estado reduzido a sua mínima expressão, o que implica, entre outras coisas, transferir os serviços públicos para o setor privado (VITULLO, 2011, p. 32).

Conforme Vitullo (2011), os principais objetivos econômicos do neoliberalismo eram alcançar maiores índices de crescimento e conseguir o controle da inflação. Para isso, foram formuladas várias medidas de cunho econômico, político, social e cultural. Uma dessas medidas foi o combate aos sindicatos, pois, segundo os neoliberais, estes afetavam o bom funcionamento dos mercados no momento em que interferiam a favor dos trabalhadores nas relações de trabalho. Outra medida foi a redução do tamanho do Estado, eliminando outras e ferindo prestações de serviços típicos do Estado para o setor privado.

A estratégia utilizada pelos neoliberais para difundir sua proposta era atuar no campo teórico, através dos encontros internacionais para discussões da doutrina; na frente política, através de agremiações partidárias que pudessem servir de veículo para a chegada ao poder; e no âmbito sociocultural, através de um trabalho de persuasão, com o auxílio de meios de comunicação. O objetivo era ganhar adeptos nas mais variadas esferas, como a empresarial, a acadêmica, entre os profissionais liberais e entre os administradores públicos. Para essa difusão das ideias neoliberais foram criadas entidades em diversos lugares do mundo para concentrar os seguidores do neoliberalismo, como, por exemplo, o Institute of Economic Affairs (IEA), criado em 1955 na Inglaterra, e o Heritage Foundation, criado em 1973 nos Estados Unidos. No Brasil, houve a criação dos Institutos Liberais a partir de 1983, em vários estados do Brasil, sendo que os principais foram os do Rio de Janeiro e São Paulo. 
O primeiro país a adotar o neoliberalismo foi o Chile, em 1973. Com a derrubada e assassinato do então presidente socialista Salvador Allende e a instauração da ditadura de Augusto Pinochet, o neoliberalismo chegou com os "Chicago Boys", grupo de economistas formados na Escola de Economia da Universidade de Chicago, liderada por Milton Friedman, um dos grandes nomes do ideário neoliberal (VITULLO, 2011). A Inglaterra em 1979, no governo de Margaret Thatcher, foi o primeiro governo democrático a implantar o neoliberalismo, com o objetivo de estabilizar a moeda e dinamizar a economia. Tais objetivos foram realizados, porém a pobreza infantil praticamente duplicou. Em 1980, o Estados Unidos adotou o modelo neoliberal com o então presidente Ronald Reagan. $\mathrm{Na}$ América Latina, a maioria dos países também adotou o neoliberalismo a partir dos anos oitenta. No caso do Brasil, especificamente, foi em 1990, com o governo de Fernando Collor de Mello. Porém, com o impeachment, perdeu força e retornou em 1995 no governo de Fernando Henrique Cardoso.

Crise de 1929, uma pausa na agenda liberal: a emergência da doutrina Keynesiana: A teoria liberal surgiu no século XVIII e demarca a ruptura dos regimes escravocrata e servil (FRIGOTTO, 2013). Baseada nas ideias de Adam Smith, o conceito de liberalismo vem do individualismo e visa à garantia da propriedade privada, a garantia dos excedentes monetários e a liberdade de usar esses excedentes. Na concepção dessa teoria, os indivíduos têm o objetivo inconsciente de atender aos próprios interesses. Assim, por meio de um trabalho eficiente poderiam produzir excedentes que viriam a gerar riqueza coletiva, prescindindo, assim, do Estado. Apenas o trabalho e esforço individuais garantiriam os meios de sobrevivência.

Com a crise econômica de 1929, nos Estados Unidos, provocada pela quebra da Bolsa de Valores, o liberalismo foi superado e uma nova doutrina surgiu: o keynesianismo. O keynesianismo consiste em uma teoria econômica do começo do século XX, baseada nas ideias do economista inglês John Maynard Keynes, que defendia a ação do Estado na economia com o objetivo de atingir o pleno emprego. Na Europa, com o fim da Segunda Guerra Mundial, o keynesianismo também entrou em cena na tentativa de sanar a crise e promover o desenvolvimento econômico e social. Conforme Delfaud (1988), o keynesianismo prega que o Estado deve intervir na economia, principalmente em áreas onde a iniciativa privada não tem capacidade ou não deseja atuar. $O$ Estado também tem um papel fundamental de estimular as economias em momentos de crise e recessão econômica.

No final da década de trinta, o Estado de Bem-Estar Social de Keynes passou a ser questionado pelos integrantes de uma nova doutrina que começava a surgir: o neoliberalismo. Para os neoliberais, a intervenção do Estado na economia e na assistência social afetaria o bom funcionamento do sistema capitalista.

Os neoliberais consideram que a única forma de dinamizar a economia capitalista passa pelo estímulo à oferta de bens e serviços, pelo estímulo àqueles que detêm o controle do capital. Proposta, esta, oposta daquilo que apregoavam os defensores do receituário keynesiano, para quem o melhor caminho para atingir elevados índices de crescimento econômico consiste em proporcionar incentivos aos demandantes de bens e serviços: os consumidores (VITULLO, 2011, p. 34). 
A doutrina econômica keynesiana enfraqueceu muito devido ao avanço do neoliberalismo, sendo que a globalização da economia contribuiu bastante para isso.

\section{A administração gerencial e a reforma do Estado}

No Brasil, a administração burocrática foi substituída pela administração gerencial, durante a Reforma do Estado. O grande nome desta reforma, iniciada nos anos noventa, foi Luiz Carlos Bresser Pereira, então ministro da Administração e Reforma do Estado (MARE), no governo de Fernando Henrique Cardoso. Bresser implantou a New Public Management, conhecida no Brasil como Nova Gestão Pública ou Gerencialismo. Da administração pública burocrática à gerencial: A administração burocrática clássica, concebida por Max Weber, foi implantada no Brasil, em 1938, com a reforma administrativa promovida por Maurício Nabuco e Luís Simões Lopes (BRESSER PEREIRA, 1996), através da criação do Departamento Administrativo do Serviço Público (DASP).

O Departamento Administrativo do Serviço Público (DASP) foi criado em um momento no qual o país passava por um redesenho institucional devido ao processo de industrialização e crescimento econômico, se fazendo necessário regular e fomentar este processo, através da criação de instituições governamentais, centralização das políticas públicas e capacitação dos funcionários. 0 DASP era vinculado à Presidência da República e incumbido de fazer um estudo dos órgãos públicos, onde realizou a classificação sistemática dos funcionários, dos demais empregados públicos e dos concursos de âmbito nacional para todas as carreiras, cargos e funções do serviço público federal.

A administração pública burocrática foi adotada com o objetivo de substituir a administração patrimonialista, onde o patrimônio público e o privado eram confundidos. O patrimonialismo era incompatível com o capitalismo industrial e as democracias parlamentares que surgiram no século XIX.

É essencial para o capitalismo a clara separação entre o Estado e o mercado; a democracia só pode existir quando a sociedade civil, formada por cidadãos, distinguese do Estado ao mesmo tempo em que o controla (BRESSER PEREIRA, 1996, p. 4).

Após a II Guerra Mundial a burocracia é reafirmada, contudo se inicia um processo de utilização de ferramentas da administração de empresas, ou seja, da área privada, na administração pública. Começam a aparecer as ideias de descentralização e de flexibilização administrativas nos governos em geral. Assim, nos anos setenta, com o início da crise do Estado, por consequência, a burocracia também entra em crise. Em resposta a essa crise, a administração pública caminha em direção ao gerencialismo.

O gerencialismo tem como premissa básica a busca pela eficiência. Para Bresser Pereira (1996), o Estado passou por uma transformação no século XX, se transformando em um grande Estado social e econômico, assumindo muitos serviços como a educação, a saúde, a cultura, a previdência e a assistência social, a pesquisa científica, a regulação do sistema econômico interno e das relações econômicas internacionais, a estabilidade da moeda e do sistema financeiro, a provisão de 
serviços públicos e de infraestrutura. Com toda essa gama de responsabilidades, a eficiência passou a ser essencial e a administração burocrática não conseguia alcançar tal eficiência.

A Reforma do Estado e a New Public Management: A partir dos anos noventa, iniciou-se um processo de reforma do Estado no Brasil, onde o principal objetivo era criar condições para que o Estado e suas instituições funcionassem melhor (DASSO JÚNIOR, 2002). Muitos países começaram a adotar programas de reforma do Estado, devido à crise fiscal e ao processo de globalização da economia. Com isso, a New Public Management, conhecida no Brasil como Nova Gestão Pública ou Gerencialismo foi a base teórica para a nova forma de gestão pública.

Dasso Júnior (2002, p. 2) dá uma definição de New Public Management - ou Gerencialismo:

Esse paradigma tem por princípios gerais a ênfase na eficiência e na elevação da performance, a introdução de mecanismos de mercado na gestão pública, a orientação por resultados, a descentralização dos controles gerenciais no sentido de maior autonomia, responsabilização e flexibilização de procedimentos, bem como uma importante distinção entre as funções de formulação (policy-making) e implementação (service delivery) das políticas públicas.

Conforme Bresser Pereira (1999), a Reforma Gerencial de 1995, iniciada no primeiro governo de Fernando Henrique Cardoso, tinha o objetivo de substituir a administração pública burocrática, misturada a práticas clientelistas ou patrimonialistas, por uma administração pública gerencial, que adota os princípios da nova gestão pública (New Public Management). Essa reforma foi definida no Plano Diretor da Reforma do Aparelho de Estado e envolve (BRESSER PEREIRA, 1999, p. 6):

a) a descentralização dos serviços sociais para estados e municípios;

b) a delimitação mais precisa da área de atuação do Estado, estabelecendo-se uma distinção entre as atividades exclusivas, que envolvem o poder do Estado e devem permanecer no seu âmbito, as atividades sociais e científicas, que não the pertencem e devem ser transferidas para o setor público não estatal, e a produção de bens e serviços para o mercado;

c) a distinção entre as atividades do núcleo estratégico, que devem ser efetuadas por políticos e altos funcionários, e as atividades de serviços, que podem ser objeto de contratações externas;

d) a separação entre a formulação de políticas e sua execução;

e) maior autonomia para as atividades executivas exclusivas do Estado que adotarão a forma de agências executivas;

f) maior autonomia ainda para os serviços sociais e científicos que o Estado presta, que deverão ser transferidos para (na prática, transformados em) organizações sociais, isto é, um tipo particular de organização pública não estatal, sem fins lucrativos, contemplada no orçamento do Estado - como no caso de hospitais, universidades, escolas, centros de pesquisa, museus, etc.;

g) assegurar a responsabilização (accountability) por meio da administração por objetivos, da criação de quase-mercados e de vários mecanismos de democracia direta ou de controle social, combinados com o aumento da transparência no serviço públi- 
co, reduzindo-se concomitantemente o papel da definição detalhada de procedimentos e da auditoria ou controle interno os controles clássicos da administração pública burocrática - que devem ter um peso menor.

Outra característica essencial dessa reforma foi a decisão de privatizar as empresas estatais que produzem bens e serviços para o mercado, além da terceirização das atividades de apoio para o setor privado, desde serviços simples como segurança e limpeza, até complexos como consultoria e serviços de computação (BRESSER PEREIRA, 1999). Esse conceito prega que é possível utilizar os instrumentos de gerenciamento privado no setor público. Levy (1997), diz que a administração gerencial procura adequar as organizações públicas ao lugar e ao momento, priorizando os resultados, através de uma maior eficiência e agilidade, além de procurar resgatar a identificação dos cidadãos para com o Estado.

\section{A especificidade da administração pública e a pedagogia da gestão pública e democrática}

Nesse item são estudadas formas de superar o modelo gerencialista da administração pública. É feita uma análise sobre a especificidade da administração pública, a qual leva à necessidade de formar o servidor público para atuar na gestão pública e não apenas adaptar programas de formação da área privada, prática que vem ocorrendo com frequência. Também é abordado sobre a pedagogia da gestão pública, que compreende práticas de cogestão entre governo e sociedade e que serviu de inspiração para a criação da REG.

Formação do servidor público para atuar na Gestão Pública: Os principais atores do contínuo processo de aperfeiçoamento do Estado são seus próprios funcionários (DÓRIA, 1994). Partindo desse pensamento, é importante ressaltar que a Administração Pública possui características próprias que precisam ser levadas em conta no momento da formulação de programas de formação para os servidores públicos. Não é recomendado importar ou adaptar ferramentas e programas da iniciativa privada. Conforme Dasso Júnior (2001), devido à especificidade do setor público, este necessita de um programa de formação em políticas públicas e ciências do governo e não de um programa adaptado da área privada. Kliksberg (1994, p. 132), também aborda sobre a especificidade do setor público: "os intentos de transladar mecanicamente tecnologias de outros setores ao setor público tem demonstrado sérias dificuldades. Há sobre isso múltiplas evidências a nível internacional".

A Resolução 01/2014 do Conselho Nacional de Educação representa um passo importante na busca pela formação apropriada dos servidores públicos. Ela institui as diretrizes curriculares nacionais do curso de graduação em Administração Pública (bacharelado), de modo que a especificidade da administração pública seja respeitada. De acordo com esta resolução, o curso deve formar para a atuação profissional voltado ao Estado, ao Governo, à Administração Pública e Políticas Públicas, à Gestão Pública, à Gestão Social e à Gestão de Políticas Públicas. Conforme o Artigo $2^{\circ}$ da resolução, são princípios fundamentais a serem atingidos pelos cursos de graduação em Administração Pública (2014, p.1): 
I - o ethos republicano e democrático como norteador de uma formação que ultrapasse a ética profissional, remetendo-se à responsabilidade pela res publica e à defesa do efetivo caráter público e democrático do Estado;

II - a flexibilidade como parâmetro das Instituições de Educação Superior, para que formulem projetos pedagógicos próprios, permitindo ajustá-los ao seu contexto e vocação regionais;

III - a interdisciplinaridade e a transdisciplinaridade que garantam a multiplicidade de áreas do conhecimento em temas como política, gestão pública e gestão social e sua interseção com outros cursos (CONSELHO NACIONAL DE EDUCAÇÃO, 2014).

Esta resolução ainda aponta que o curso de graduação em Administração Pública deve propiciar formação humanista e crítica, tornando os profissionais aptos a atuar como políticos, administradores ou gestores públicos.

Além disso, os servidores públicos necessitam de uma formação que os instigue a ter visão crítica e capacidade de analisar os problemas e paradigmas próprios da gestão pública, e não apenas uma formação baseada em competências que assegure a empregabilidade. Na visão de Frigotto (2013, p. 9):

O campo da qualificação, capacitação e, mais amplamente do educativo da escola básica à pós-graduação, no quadro do ajuste global, é direcionado para uma concepção produtivista, cujo papel é o de desenvolver habilidades de conhecimento, de valores e atitudes e de gestão da qualidade, definidas no mercado de trabalho e cujo objetivo é o de formar em cada indivíduo um banco ou reserva de competências que Ihe assegure empregabilidade.

Nesse contexto, as escolas de governo têm um papel fundamental, pois disseminam o conhecimento em gestão pública, bem como o desenvolvimento de competências profissionais dos que compõem o Estado (FERRAREZI; TOMACHESKI, 2010). O governo deve fazer sua parte para efetivar a democratização da gestão pública e, nessa tarefa, as escolas de governo têm um importante papel:

As Escolas de Governo têm sido um espaço privilegiado para tais iniciativas por parte dos governos. Ao assumirem o papel educador do Estado, tais governos através de iniciativas de formação dos atores envolvidos, contribuem para o avanço da construção de uma cidadania ativa e de uma democracia substantiva (PONTUAL, 2012, p. 2).

Pedagogia da Gestão Pública e Democrática: A Pedagogia da Gestão Pública e Democrática é, conforme, Pontual (2012), a construção de uma nova cultura política, onde os atores (da sociedade civil e do governo) possam dialogar com o objetivo de adquirir eficácia e potência de ação no exercício da democracia e da cidadania ativa. Alguns elementos construtivos desta pedagogia são: 
a) é metodologicamente deliberativa, ou seja, ela deve proporcionar a possibilidade efetiva do exercício de decidir sobre os assuntos públicos;

b) deve estimular práticas de cogestão (entre governo e sociedade), desenvolvendo a atitude de corresponsabilidade e a prática de parceria entre os atores sociais na resolução de problemas e construção de alternativas para o desenvolvimento com equidade e sustentabilidade;

c) é uma pedagogia do público, da construção do sentido do comum, a partir da construção de esferas públicas transparentes e democráticas, em que se exercita a deliberação a partir de critérios objetivos, compartilhados e impessoais;

d) se realiza no próprio exercício da cidadania ativa, desenvolvendo a consciência de que tomar conta do seu País e da sua comunidade é um direito (que inclui a corresponsabilidade) e que, quando ele é exercido, as coisas acontecem;

e) busca formar cidadãos autônomos e críticos, com capacidades comunicativas e argumentativas para participar de instituições da sociedade civil, para exercer associativamente o controle sobre governos e resolver pacificamente e democraticamente os conflitos;

f) instrumentaliza os atores da sociedade civil e dos governos para novas formas de exercício do poder em que a transparência das ações, a capacidade de escutar, dialogar, reconhecer legitimidade no outro são atitudes indispensáveis;

g) propicia a apropriação de conhecimentos técnico-políticos que ampliam a capacidade dos cidadãos de atuarem como agentes na definição e cogestão das políticas públicas;

h) amplia os conhecimentos sobre o território (bairro/cidade/região/estado/País) e seus diversos elementos de identidade, facilitando a ação integrada das políticas públicas e a participação e controle dos cidadãos sobre as mesmas;

i) desenvolve a autoestima, as capacidades de comunicação e relacionamento interpessoal e assim cria motivação pessoal para participação em ações coletivas;

j) desenvolve os valores de solidariedade, justiça, união, respeito ao outro, tolerância, humildade, esperança, abertura ao novo, disponibilidade à mudança como elementos de uma ética universal que deve estar na base das ações de educação para a cidadania (PONTUAL, 2012, p. 8).

A Pedagogia da Gestão Pública e Democrática tem como principal objetivo superar o modelo gerencialista da administração pública, buscando que o Estado não coloque os interesses privados acima dos interesses públicos. Esse modelo de gestão também busca incluir a sociedade em geral no contexto da administração pública, atuando como cidadãos ativos, que participem e sejam capazes de julgar e fazer escolhas. Conforme Branco e Bitencourt (2014, p. 30):

A Pedagogia da Gestão Pública e Democrática tem por objetivo formar sujeitos capazes de ter reflexão crítica sobre o meio em que vivem e, assim, empoderá-los da capacidade de transformar este meio de forma mais imediata e, por conseguinte, a sociedade. 
Assim, no modelo em questão, a união entre governo e sociedade é incentivada, pois a responsabilidade de gestão passa a ser de ambas as partes. Há o fortalecimento da democracia, onde a sociedade participa ativamente das decisões, não sendo apenas sujeito passivo. Freire (1996) também aborda a questão, ressaltando o papel da educação na sua relação com a cidadania, que a formação continuada se faz necessária, pois traz a reflexão sobre a realidade. Essa reflexão realizada por cidadãos ativos e críticos poderá gerar ações para mudar a realidade. Para Frigotto (2013), a formação e capacitação que desenvolve sujeitos autônomos e solidários e cidadãos ativos tem como desafio trabalhar dimensões ético-políticas, ou seja, trabalhar na afirmação de valores de igualdade, solidariedade e defesa do espaço público.

\section{Materiais e Métodos}

O objetivo deste estudo foi analisar como a Rede Escola de Governo (REG) do Rio Grande do Sul, em sua atuação no período de 2011 a 2014, representa uma tentativa de superação do modelo gerencialista da Administração Pública. A pesquisa tem uma abordagem qualitativa e descritiva. Para Godoy (1995), no enfoque qualitativo não há a utilização de medição numérica para medir os eventos estudados. Segundo Neves (1996), o desenvolvimento de um estudo de pesquisa qualitativa supõe um corte temporal-espacial de determinado fenômeno por parte do pesquisador.

Foi utilizado o método do estudo de caso proposto por Yin (2010), que consiste em uma investigação empírica, observando um fenômeno contemporâneo dentro de seu contexto da vida real. A coleta de dados foi realizada no período ente janeiro de 2015 e maio de 2015 . Conforme Vergara (2000), a pesquisa bibliográfica é realizada através da análise de material disponível em livros, artigos científicos, revistas e sítios da internet, entre outros, e foi utilizada para consolidar o referencial teórico do estudo em questão.

\section{Resultados e Discussão}

Neste item, busca-se analisar como a Rede Escola de Governo (REG) procura superar o modelo gerencialista da Administração Pública. Para tanto, são descritos alguns dados gerais sobre a REG, bem como suas origens. Na sequência, é feito uma crítica a respeito do gerencialismo e, por último, analisado como a REG atua para atingir o objetivo de superar o gerencialismo.

\section{Rede Escola de Governo (REG): suas origens}

A Rede Escola de Governo (REG) é um projeto estratégico do governo, criada através da Lei no 13.824 , de 27 de outubro de 2011. O seu principal objetivo é promover a formação continuada voltada aos servidores públicos e agentes sociais, em parceria com instituições de ensino superior, através da realização de cursos de extensão, especialização, seminários e oficinas. A coordenação executiva e pedagógica da REG é responsabilidade da Fundação para o Desenvolvimento de Recursos Humanos (FDRH), fundação pública de direito privado criada a fim de promover o desenvolvimento dos recursos humanos do estado do Rio Grande do Sul, no ano de 1972. 
A REG é um projeto que consta no Plano Plurianual - PPA 2012/2015 como um Programa Rede Escola de Governo: Qualificação e Formação Continuada de Servidores Públicos e Agentes Sociais, que tem os objetivos de:

\footnotetext{
Viabilizar a formação continuada para servidores públicos e agentes sociais e promover ações formativas que desenvolvam competências para o contexto da Copa do Mundo de 2014. Reconstituir e modernizar a FDRH, remodelar a Gestão dos Estágios e Concursos Públicos (RIO GRANDE DO SUL, 2011, p. 209).
}

Sua criação foi baseada na Constituição Federal de 1988 (BRASIL, 1988), onde seu art. 39, parágrafo segundo determina que:

\footnotetext{
A União, os Estados e o Distrito Federal manterão escola de governo para formação e aperfeiçoamento dos servidores públicos, constituindo-se a participação nos cursos um dos requisitos para promoção na carreira, facultada, para isso a celebração de convênios ou contratos entre os entes federados.
}

A REG funciona em rede, através da parceria com 33 instituições de ensino superior de todo o estado do Rio Grande do Sul que desenvolvem programas de formação sobre diferentes temas, oferecendo cursos de extensão e especialização, atividades de ensino (seminários, oficinas, congressos, encontros), todos devidamente certificados pela FDRH e a instituição de ensino parceira, fomento à pesquisa voltada ao setor público e produção de publicações científicas. Busca a construção de novos conhecimentos, a partir dos saberes acadêmicos e dos saberes construídos no serviço público (BRANCO; BITENCOURT, 2014). Oferece formação não só aos servidores públicos, como também, aos agentes sociais, por acreditar que estes indivíduos ou grupos interagem com o Estado na condução, no controle e na execução de propostas de políticas públicas e de projetos sociais. Desde sua criação, 22 mil alunos participaram de programas da REG, 10 cursos de especialização foram concluídos ou estão em andamento, 262 cursos de extensão foram realizados e 400 municípios foram beneficiados.

\section{Gerencialismo como solução para os problemas da Administração Pública?}

O modelo gerencial busca disseminar a ideia de que o que é privado é melhor que o público, ou seja, que trazer ferramentas da área privada para a pública é sinônimo de eficiência. Porém, a gestão pública tem sua especificidade e não pode ser uma mera importadora de modelos da gestão privada. O professor Gabriel Vitullo traz a seguinte reflexão: "É possível a ampliação do processo democrático sob o império do modelo neoliberal? Sob o império, no caso específico da administração pública, do modelo gerencial? " (Informação verbal fornecida por Gabriel E. Vitullo em aula inaugural do curso de Especialização em Gestão Pública e Democracia da UERGS, Porto Alegre, em agosto de 2013.). Para Vitullo (2011), o neoliberalismo conseguiu uma importante redução dos índices de inflação, especialmente na América Latina, porém não conseguiu garantir um crescimento sustentado da 
economia. Portanto, a ideia de que os mercados são eficientes e que estes devem regular a economia, fazendo com que o Estado fique em segundo plano, parece não ser verdadeira.

O modelo gerencialista não se mostra capaz de capacitar o servidor público para atuar como mediador entre Estado e sociedade, pois prioriza somente as técnicas da gestão e do aperfeiçoamento de processos de trabalho. Conforme, Pontual (2012), é preciso priorizar o ensino de conhecimentos técnico-políticos, trazendo o diálogo e a participação de todos os agentes públicos, ou seja, de toda a sociedade.

\section{Rede Escola de Governo (REG): superando o modelo gerencialista da Adminis- tração Pública}

O ideal de construção da REG é superar o modelo gerencialista, tornando o servidor público um agente capaz de atuar como mediador entre Estado e sociedade de forma transparente, democrática e participativa, e assim, buscar um novo conceito por parte da sociedade sobre o servidor e o serviço público. Para atingir tal objetivo, a REG adotou como concepção teórica para sua criação, o modelo da pedagogia da gestão pública e democrática. Esse modelo busca a construção de uma pedagogia própria para a gestão pública. Assim, não é utilizado apenas a adequação ou a customização de ferramentas gerenciais adaptadas da iniciativa privada, mas sim, construído um programa de formação próprio para a gestão pública, levando em consideração a especificidade desse setor. O objetivo geral da REG, conforme Branco e Bitencourt (2014, p.56), é:

Consolidar a Rede Escola de Governo, assentada na Pedagogia da Gestão Pública e Democrática, através de uma rede integrada de formação continuada na administração pública.

A pedagogia da gestão pública e democrática adotada pela REG busca, através da formação continuada dos servidores públicos, resgatar a democracia plena, ou seja, resgatar o sentido da esfera pública e do serviço público. Para isso, visa romper com a "modernização conservadora" que o neoliberalismo produz através do gerencialismo. Para Frigotto (2013, p. 1):

Trata-se de uma postura que se opõe frontalmente às Reformas de Estado fundadas no credo neoliberal, já que as mesmas se definem pelo desmonte da esfera pública e, consequentemente, da esfera dos direitos sociais.

Levando em consideração que o setor público possui suas especificidades e, para a REG, isso é algo de extrema importância, o conteúdo pedagógico dos programas de formação continuada é baseado no conceito de um Estado promotor das garantias sociais, democrático, transparente e submetido ao controle da sociedade (BRANCO; BITENCOURT, 2014). Para o Estado, o interesse público deve estar acima do privado.

A REG busca mais que treinamento e capacitação, busca uma formação que dê aos servidores públicos a capacidade de ter uma visão crítica, a capacidade de dialogar com os demais atores 
do governo e da sociedade. O intuito é formar para fortalecer a cidadania e a democracia, superando o uso de estratégias e ferramentas gerenciais. O modelo em rede da REG busca esse diálogo, através da parceria, universalidade, descentralização e pluralidade entre Estado, instituições de ensino superior (IES) e sociedade (BRANCO; BITENCOURT, 2014).

A REG não é uma escola formal, legitimada pelas regras e leis da educação nacional, mas uma rede (daí o conceito Rede Escola de Governo) articuladora dos conhecimentos produzidos nas universidades gaúchas - estas, sim, legal e formalmente instituídas. Todavia, ela está apoiada em uma pedagogia (BRANCO; BITENCOURT, 2014, p.53).

Esse formato faz com que as decisões sobre o conteúdo dos programas e ações educativas não sejam unilaterais. Cada IES é responsável por uma área temática de acordo com seu acúmulo em pesquisa, experiência de extensão comunitária e localização em territórios específicos (BRANCO; BITENCOURT, 2014, p. 19). Assim, o trabalho em rede também atinge um número maior de servidores públicos, em diversas regiões do Rio Grande do Sul e nas diferentes áreas de atuação. A parceria com as IES promove a disseminação do conhecimento.

\section{Conclusão}

Este trabalho teve por objetivo analisar a experiência da Rede Escola de Governo (REG) do Rio Grande do Sul quanto ao seu objetivo de superar o modelo gerencialista da Administração Pública. A metodologia se mostrou adequada, pois através da pesquisa bibliográfica, obteve-se o material necessário para o objetivo do estudo. Constatou-se que o neoliberalismo ainda não está superado, portanto o gerencialismo continua a ser praticado na Administração Pública.

Quanto à REG, objeto deste estudo, identificou-se que a mesma adotou práticas que auxiliam na superação do gerencialismo. Através da pedagogia da gestão pública e democrática, vem construindo canais de diálogo entre a sociedade e o governo e, através de seu modelo em rede, atinge servidores públicos em grande parte do estado do Rio Grande do Sul. Como pontos fortes, pode-se destacar que a REG já atingiu 22 mil alunos com seus programas de formação. Outro importante fator é que possui programas em consonância com a especificidade do setor público e vem formando servidores para atuarem na Administração Pública e não apenas adaptando formações da área privada. Um exemplo disso é o curso de Especialização em Gestão Pública e Democracia, realizado em parceria com a Universidade Estadual do Rio Grande do Sul (UERGS), voltado para servidores públicos em âmbito estadual. Contudo, pode-se esperar que a pedagogia da gestão pública e democrática não será necessariamente seguida por todas as gestões do governo estadual, podendo-se adotar novas concepções, pois outras gestões poderão não ter o objetivo de superar o gerencialismo e nem todas as escolas de governo que existem atualmente possuem programas de formação que objetivam superar o gerencialismo. Para finalizar, considera-se que a continuidade deste trabalho inclui um estudo mais aprofundado sobre outras formas de superar o gerencialismo na Administração Pública. 


\section{Referências}

BRASIL. Resolução n. 01/2014, de 13 de janeiro de 2014 - Institui as Diretrizes Curriculares Nacionais do curso de graduação em Administração Pública, bacharelado, e dá outras providências. Disponível em: <http://www.portal.mec.gov.br/ConselhoNacionaldeEducacao>. Acesso em: 28 jul. 2015.

BRESSER PEREIRA, L. C. Da administração pública burocrática à gerencial. Revista do Serviço Público, v. 47, n. 1, p. 1-28, jan./abr. 1996.

Reflexões sobre a reforma gerencial brasileira de 1995. Revista do Serviço Público, v. 50, n. 4, p. 5-29, out./dez. 1999.

BRANCO, J.; BITENCOURT, S. Rede Escola de Governo: ação e formação para um Estado público. Porto Alegre: Corag, 2014.

DASSO JÚNIOR, A. E. O papel das escolas de governo na Reforma do Estado. Opinio: Revista de Ciências Empresariais, Políticas e Sociais, v. 1, n. 7, p. 41-51, jul./dez. 2001.

DASSO JÚNIOR, A. E. O papel do servidor público num Estado democrático e participativo. Painel: "Conversando sobre gestión pública: directivos, innovación y cambio em el proceso de modernización del Estado: enfoques y perspectivas". VII CONGRESO INTERNACIONAL DEL CLAD SOBRE LA REFORMA DEL ESTADO Y DE LA ADMINISTRACIÓN PÚBLICA, Lisboa, Portugal, 8-11 Oct. 2002. Disponível em:

<http://unpan1.un.org/intradoc/groups/public/documents/CLAD/clad0043625.pdf>. Acesso em: 21 maio 2015.

DELFAUD, P. Keynes e o keynesianismo. [S.I.]: Europa-América, 1988.

DÓRIA, O. R. Ética e profissionalização: a retomada da credibilidade da administração pública. Revista do Serviço Público, v. 45, n. 1, p. 143-154, 1994.

FERRAREZI, E.; TOMACHESKI, J. A. Mapeamento da oferta de capacitação nas escolas de governo no Brasil: gestão da informação para fortalecimento da gestão pública. Revista do Serviço Público, v. 61, n. 3, p. 287-303, jul./set. 2010.

FUNDAÇÃO PARA O DESENVOLVIMENTO DE RECURSOS HUMANOS (FDRH). Disponível em: <http://www.fdrh.rs.gov.br/>. Acesso em: 22 mar. 2015.

FREIRE, P. Pedagogia da autonomia: saberes necessários à prática educativa. São Paulo: Paz e Terra, 1996.

FRIGOTTO, G. Política de capacitação do servidor público: uma alternativa metodológica à doutrina neoliberal. Artigos e publicações sítio eletrônico da Rede Escola de Governo (REG), Porto Alegre, 2013. Disponível em: <http://redeescoladegoverno.fdrh.rs.gov.br/conteudo/1568>. Acesso em: 22 jan. 2015.

GODOY, A. S. Pesquisa qualitativa: tipos fundamentais. Revista de Administração de Empresas, v. 35, n. 3, p. 20-29, mai./jun. 1995.

KLIKSBERG, B. Uma gerência pública para os novos tempos. Revista do Serviço Público, v. 45, n. 1, p. 119-142, 1994.

LEVY, E. Formação e capacitação na construção de um novo Estado. Brasília: MARE/ENAP, 1997.

NEVES, J. L. Pesquisa qualitativa: características, usos e possibilidades. Caderno de pesquisas em Administração, v. 1, n. 3, p. 1-5, 1996. 
PONTUAL, P. Estratégias e metodologias de formação na construção de uma Pedagogia da Gestão Democrática. Artigos e publicações sítio eletrônico da Rede Escola de Governo (REG), Porto Alegre, 2012. Disponível em:

<http://redeescoladegoverno.fdrh.rs.gov.br/upload/1367263532_201202_PedroPontual.pdf >. Acesso em: 02 jun. 2015.

REDE ESCOLA DE GOVERNO (REG). Disponível em:

<http://www.redeescoladegoverno.fdrh.rs.gov.br/>. Acesso em: 22 mar. 2015.

RIO GRANDE DO SUL. Plano Plurianual Participativo 2012-2015. Disponível em:

<http://www1.seplag.rs.gov.br/upload/PPA2012-2015-\%20para\%20site_concluido.pdf>. Acesso em: 12 jan. 2015.

VERGARA, S. C. Projetos e relatórios de pesquisa em Administração. 3. ed. São Paulo: Atlas, 2000.

VITULLO, G. E. Ascensão, auge e decadência do neoliberalismo na América Latina. Cadernos Pet: artigos acadêmicos, v. 5, p. 31-48, 2011.

YIN, R. K. Estudo de caso: planejamento e métodos. 4. ed. Porto Alegre: Bookman, 2010. 